\title{
Extended wear soft contact lenses induce corneal epithelial changes
}

\author{
Kazuo Tsubota, Ikuko Toda, Hiroshi Fujishima, Masakazu Yamada, Tokuaki Sugawara, \\ Jun Shimazaki
}

\begin{abstract}
The purpose of this study was to determine the corneal epithelial alterations induced by various types of contact lenses. By employing the specular microscope, the corneal epithelia of 60 patients who had worn contact lenses for more than 1 year were re-examined along with 15 myopic controls. The morphological changes in aphakic patients who changed from extended wear soft to extended wear rigid gas permeable lenses were also studied. The mean cell area of the corneal epithelium was 621.5 (SD 92.5) $\mu^{2}$ for daily wear rigid gas permeable lenses $(n=15), 645.8$ (98.1) $\mu \mathrm{m}^{2}$ for daily wear soft lenses $(n=15)$, and $634.7(88.6) \mu \mathrm{m}^{2}$ for extended wear rigid gas permeable lenses $(n=15)$, none of which differed significantly from the control value of $610.5(98.1) \mu \mathrm{m}^{2}$. Only the extended wear soft lens group $(n=15)$ showed significantly enlarged epithelia (806.1 (50.1) $\mu \mathrm{m}^{2}, \mathrm{p}<0.01$ versus the other groups). The epithelium partially returned to normal after changing from extended wear soft lenses to extended wear rigid gas permeable ones. The corneal epithelium showed increased cell area only with extended wear soft contact lenses which are known to pose a risk for corneal infection. (Br F Ophthalmol 1994; 78: 907-911)
\end{abstract}

Recently, there has been an increase in the number of reported contact lens related corneal ulcers. ${ }^{1-3}$ Although the incidence of such ulcers is low it means that there are many individuals affected, given the tens of millions of contact lens wearers in the United States, Japan, and other industrialised countries. As contact lenses become increasingly popular, it is necessary to investigate the risk factors for related problems and how such complications may be minimised.

Among the various kinds of contact lenses, extended wear soft contact lenses (EWSCL) seem to carry the greatest risk for causing corneal problems. ${ }^{4}$ Poggio et al reported that the incidence of ulcerative keratitis was $4 \cdot 1 / 10000$ person years for daily wear soft contact lens (DWSCL) wearers, whereas it was $20.9 / 10000$ person years in the EWSCL group. ${ }^{45}$ From the Moorfields Eye Hospital, Dart et al found that the relative risk for overnight wear soft lenses was 21 , for daily wear soft lenses $3 \cdot 6$, and for polymethylmethacrylate hard lenses $1.3 \mathrm{com}$ pared with gas permeable hard lenses.'

The risk of extended wear lenses may be due to several mechanisms. Although the permeability of oxygen through contact lenses has been greatly increased, the extended wear lenses may not maintain the ideal oxygen pressure during sleep. ${ }^{6}$ Another possibility is the mechanical effect on the corneal epithelium. During sleep, the production of tears decreases and the ocular surface is thus more susceptible to infection. ${ }^{7}$ Furthermore, prolonged contact lens wear itself may increase bacterial transfer from the lenses, for which bacteria have a known affinity. ${ }^{8}$

There is empirical evidence for corneal damage caused by certain types of contact lenses, and attempts have been made to correlate this with changes in corneal thickness, sensitivity, and fluorescein permeability. However, there has been no reliable indicator for assessing corneal epithelial viability and detecting subtle alterations that may presage complications. Also, while corneal endothelial morphology has some relation with that of the epithelium, ${ }^{9}$ and endothelial changes associated with contact lens wear have been reported, ${ }^{10-12}$ these changes are not related to ulcer formation.

Specular microscopy is a promising method of evaluating subtle changes in the corneal epithelium. This non-invasive method permits in vivo observation of the epithelium at the cellular level. Using this technique, Lemp et $a l^{13}$ and Tsubota $e t a l^{14}$ showed that the number of large epithelial cells increase in users of EWSCL. However, a comparative study with age and sex matched controls has not been performed.

In this study, we employed specular microscopy to examine epithelial morphology associated with several types of contact lenses. We also investigated the effect on the corneal epithelium of changing from EWSCL to extended wear rigid gas permeable contact lenses (EWRCL) in aphakic patients.

\section{Materials and methods}

PATIENTS AND CONTACT LENSES

In the first part of the study, 60 eyes from 60 myopic, but otherwise healthy, people were enrolled. They were divided into four groups: (1) daily wear rigid gas permeable contact lenses

Table 1 Group statistics

\begin{tabular}{llll}
\hline & $\begin{array}{l}\text { Average age } \\
\text { (years) }(S D)\end{array}$ & $\begin{array}{l}\text { Sex } \\
\text { (male:female) }\end{array}$ & $\begin{array}{l}\text { Average } \\
\text { lens wear } \\
\text { (years) }(S D)\end{array}$ \\
\hline DWRCL & $31 \cdot 7(7 \cdot 9)$ & $5: 10$ & $2 \cdot 3(1 \cdot 2)$ \\
DWSCL & $24 \cdot 1(6 \cdot 4)$ & $6: 9$ & $2 \cdot 1(1 \cdot 0)$ \\
EWRCL & $32 \cdot 8(8 \cdot 9)$ & $4: 11$ & $1 \cdot 8(0 \cdot 8)$ \\
EWSCL & $26 \cdot 3(7 \cdot 3)$ & $6: 9$ & $2 \cdot 1(1 \cdot 3)$ \\
Control & $27 \cdot 9(8 \cdot 4)$ & $6: 9$ & None \\
EWSCL (aphakia) & $62 \cdot 3(10 \cdot 1)$ & $6: 9$ & $3 \cdot 2(1 \cdot 5)$ \\
Control (aphakia) & $57 \cdot 9(8 \cdot 4)$ & $6: 9$ & None
\end{tabular}

DWRCL $=$ daily wear rigid contact lens; DWSCL $=$ daily wear soft contact lens; $E W R C L=$ extended wear rigid contact lens; EWSCL $=$ extended wear soft contact lens. 
Table 2 Contact lenses

\begin{tabular}{|c|c|c|c|c|c|}
\hline Group & Material & $D k^{\star}$ & $\begin{array}{l}\text { Average } \\
\text { central } \\
\text { thickness } \\
(\mathrm{mm})\end{array}$ & $\begin{array}{l}\text { Diameter } \\
(\mathrm{mm})\end{array}$ & $\begin{array}{l}\text { Water } \\
\text { content }\end{array}$ \\
\hline $\begin{array}{l}\text { DWRCL } \\
\text { DWSCL } \\
\text { EWRCL } \\
\text { EWSCL }\end{array}$ & $\begin{array}{l}\text { MMA+SMA } \\
\text { P-HEMA } \\
\text { FMA } \\
\text { HEMA + VP }\end{array}$ & $\begin{array}{r}30 \cdot 0 \\
8 \cdot 5 \\
58 \cdot 0 \\
64 \cdot 0\end{array}$ & $\begin{array}{l}0 \cdot 14 \\
0 \cdot 05 \\
0 \cdot 16 \\
0 \cdot 20\end{array}$ & $\begin{array}{r}8 \cdot 8 \\
13 \cdot 5 \\
8 \cdot 8 \\
13 \cdot 5\end{array}$ & $\begin{array}{r}0 \% \\
39 \% \\
0 \% \\
78 \%\end{array}$ \\
\hline
\end{tabular}

*Unit of $\mathrm{Dk}$ is $\times 10^{-11} \mathrm{~cm}^{2} / \mathrm{s}\left(\mathrm{ml} \mathrm{O}_{2} / \mathrm{ml} \times \mathrm{mm} \mathrm{Hg}\right)$.

MMA = methylmethacrylate; SMA = siloxanile methacrylate; P-HEMA = polyhydroxyethyl methacrylate; FMA = fluoromethacrylate; $\mathrm{VP}=$ vinyl pyloridone.

Table 3 Morphometric analysis of corneal epithelium and endothelium: effects of different lens types

\begin{tabular}{lll}
\hline Group & Epithelium $\left(\mu \mathrm{m}^{2}\right)$ & Endothelium $\left(\mu \mathrm{m}^{2}\right)$ \\
\hline Control & $610 \cdot 5(98 \cdot 1)$ & $312 \cdot 5(56 \cdot 1)$ \\
DWRCL & $621 \cdot 5(92 \cdot 5)$ & $315 \cdot 3(48 \cdot 1)$ \\
DWSCL & $645 \cdot 8(98 \cdot 1)$ & $316 \cdot 3(33 \cdot 2)$ \\
EWRCL & $634 \cdot 7(88 \cdot 6)$ & $339 \cdot 0(38 \cdot 4)$ \\
EWSCL & $806 \cdot 1(50 \cdot 1)^{\star}$ & $309 \cdot 3(24 \cdot 9)$ \\
\hline
\end{tabular}

Figure 1 Typical specular
microscopic photographs of the corneal epithelium in control and different contact lens groups. Epithelia are hexagonal and reveal a regular configuration. Only the EWSCL group showed relatively larger cells. Bar= $100 \mu \mathrm{m}$. (A) Control (female, 24 years old); ( $\left.A^{\prime}\right)$ Control male, 28); (B) DWRCL (female, 27); (C) DWSCL (female, 26) (D) EWRCL (female, 30); (E) EWSCL (female, 24), $\left(E^{\prime}\right) E W S C L$ (male, 33).

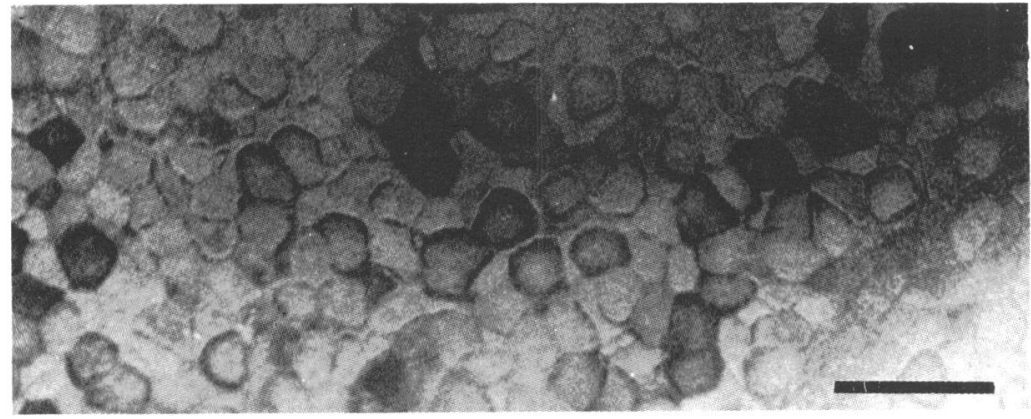

Fig $1 A$
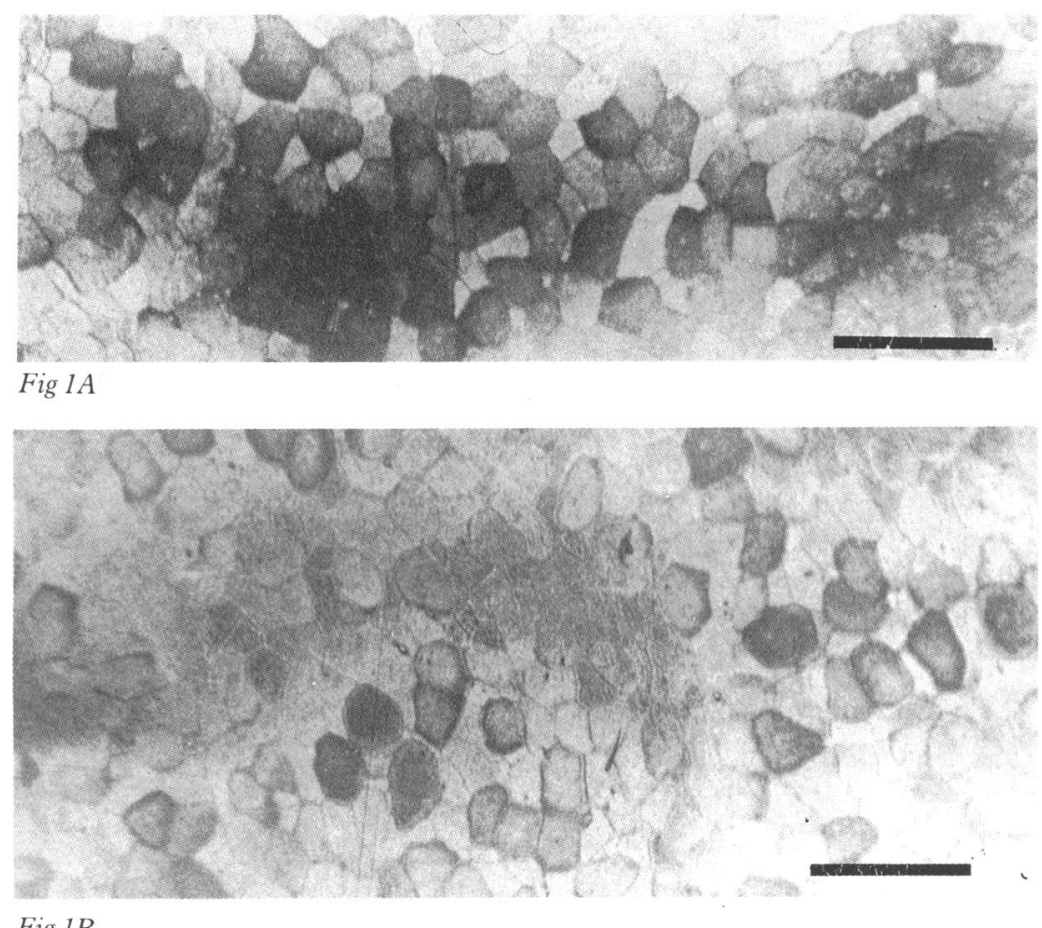

tinuously for 1 week. Age and sex matched patients (six male, nine female; $27.9(8.4)$ years old) who were contact lens candidates, and had only myopia or myopic astigmatism, served as controls (Table 1).

The contact lenses used in this study were as follows: daily wear rigid gas permeable (methylmethacrylate+ polyxyloxanyl polymer) for the DWRCL group, hydrophilic soft (polyhydroxy ethylmethacrylate) for the DWSCL group, extended wear rigid gas permeable (fluoromethacrylate) for the EWRCL group, and high water content hydroxymethyl ethacrylate for the EWSCL group. The material, Dk (oxygen permeability), lens thickness, diameter, and water content are shown in Table 2.

In the second, prospective portion of our study, 15 aphakic patients (six male, nine female; $62 \cdot 3(10 \cdot 1)$ years old) were enrolled (Table 1). Their average refractive error was 13.0 (3.6) dioptres, and they had been wearing the same EWSCL, for an average of $3 \cdot 2$ years, after cataract extraction (five intracapsular and 10 extracapsular). The corneal epithelium was normal by routine slit-lamp examination. One patient had vitreous loss during the surgery, but without sequelae. After specular microscopic observation, all patients changed their EWSCL to EWRCL (Haisanso, Rainbow Contact Lens, Ltd, $\mathrm{Dk}=58$, diameter $=8.8 \mathrm{~mm}$, central thickness $=0.16 \mathrm{~mm}$ ) and the same examinations were performed 3 months after. For the controls in this study, 15 patients (six male, nine female, $57.9(8.4)$ years old) who had not worn any contact lenses after surgery were enrolled. All had had extracapsular cataract extraction with posterior chamber intraocular lens insertion.

\section{SPECULAR MICROSCOPY}

The centres of the corneal epithelium and endothelium were observed by wide field specular microscopy (Keeler-Konan Specular Microscope, Nishinomiya, Japan) with a specular microscopic contact lens, ${ }^{15} 16$ and photographed with Kodak Tri-Max film.

Morphometric analysis of the images was performed using a Keeler Konan cell analysis system. The mean cell area and coefficient of variation of mean cell area were calculated using at least 50 cells in the epithelium and 100 cells in the endothelium. Qualitative evaluation of the epithelium involved checking for the presence of elongated and large cells, which are not observed in the normal epithelium. ${ }^{9}$

\section{Results}

The average cell areas of the superficial corneal epithelium were $621.5(92.5) \mu \mathrm{m}^{2}$ in the DWRCL group and $634.7(88.6) \mu \mathrm{m}^{2}$ in EWRCL group, both of which were in the same range as that of the normal control group, 610.5 $(98 \cdot 1) \mu \mathrm{m}^{2}$ (Table 3). The mean cell area of the DWSCL group was $645 \cdot 8(98 \cdot 1) \mu \mathrm{m}^{2}$, statistically insignificantly larger than that of the control group. Only the EWSCL group showed an enlarged epithelial cell size, $806 \cdot 1(50 \cdot 1) \mu \mathrm{m}^{2}$ (unpaired $t$ test, $\mathrm{p}<0.01$ compared with each of the other groups). 


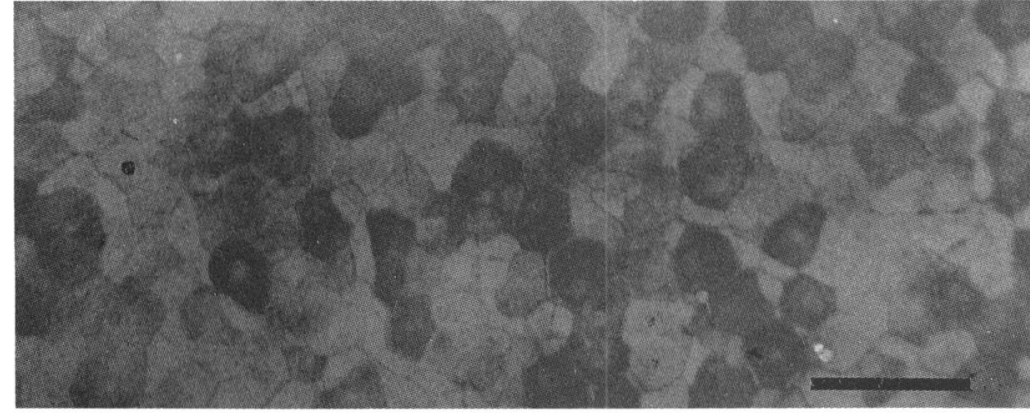

Fig $1 C$

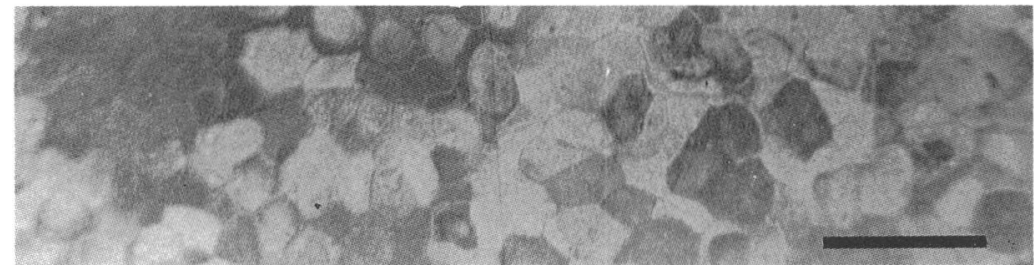

Fig $1 D$

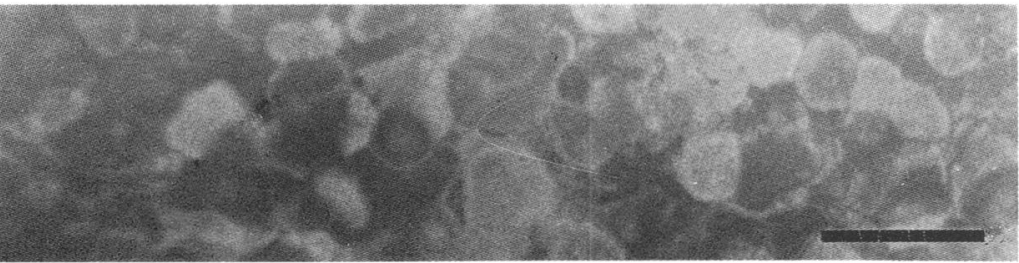

Fig $1 E$

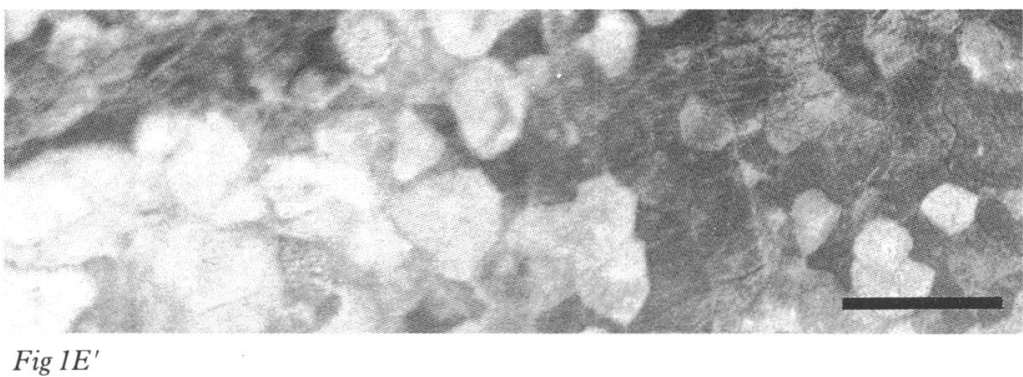

The typical corneal epithelial cell patterns in each group are shown in Figures $1 \mathrm{~A}-\mathrm{E}^{\prime}$. The cells are hexagonal and almost the same size except for the EWSCL group. There were no elongated epithelial cells in any groups. The endothelial cells did not show any difference before and after contact lens wear (Table 3).

The average cell area of aphakic patients with EWSCL was $887.9(156.4) \mu \mathrm{m}^{2}$, which was significantly larger (unpaired $t$ test, $\mathrm{p}<0.01$ ) than that of the aphakic controls, $654 \cdot 6(124 \cdot 4)$ $\mu \mathrm{m}^{2}$ (Table 4). After the patients changed from EWSCL to EWRCL, their mean epithelial cell area decreased to $750 \cdot 1(125 \cdot 1) \mu \mathrm{m}^{2}$, which was still larger than that of the controls but was significantly less than the EWSCL (unpaired $t$ test, $\mathrm{p}<0.05$ ). The epithelia of controls and typical cases are shown in Figures 2A-D. Elongated cells were observed in eight (53.3\%) cases and large cells in all $15(100 \%)$ cases with EWSCL. After the contact lens change, these percentages dropped to $13.3 \%$ and $26.6 \%$, respectively (Table 5). The endothelial cells did not show any difference before or after contact lens change (Table 4).

\section{Discussion}

Using specular microscopy, we have demon- strated that EWSCL induce corneal epithelial changes. The cell area of the superficial layer of the corneal epithelium was enlarged with EWSCL, whereas no significant changes were observed with other types, including EWRCL, DWRCL, and DWSCL. Furthermore, we have shown that the development of large and elongated epithelial cells in aphakic patients partially resolves after changing from EWSCL to EWRCL.

Although contact lenses have several optical advantages over spectacles, their use requires some caution. The most serious risk of contact lenses is ulcerative keratitis, ${ }^{1-5}$ 17-19 which is an ulceration of the corneal epithelium with an underlying stromal infiltration. Most of the increase in lens associated ulcers is thought to be attributable to EWSCL. ${ }^{4}$ It is thus not surprising that the EWSCL group in our study had the most serious changes in epithelial morphology. The subtle epithelial changes, such as increased cell size may portend epithelial vulnerability and accelerated bacterial attachment ${ }^{20}$ which would increase the risk of ulceration.

The mechanism of cell enlargement is not clear, but possibilities include altered mitotic rate caused by the lower oxygen pressure, ${ }^{21}$ accelerated differentiation, and sustained desquamation induced by mechanical coverage. ${ }^{1314}$ The decreased oxygen level on the surface of the epithelium may be the primary mechanism, but this cannot explain the differences between the gas permeable rigid and soft lenses, which have almost the same Dk. Since the largest difference between rigid and soft lenses is that the latter cover the epithelium up to the limbus with less movement, their different effects on the epithelium may be due to greater suppressed desquamation with soft lenses, which can prolong the lifetime of superficial cells (Fig 3). Suppressed desquamation may result in increased permeability to water and increased rates of infection, and subtle trauma. The superficial epithelial layer first appears at the surface with a lot of microvilli, which are seen as the dark cells with the specular microscope..$^{22}$ The superficial cells lose their microvilli with aging and begin to slough off. When proper desquamation is impeded, the surface cells become hypermature, with fewer microvilli, and correspondingly less mucin, and hence increased affinity for bacteria. ${ }^{2324}$

The EWRCL did not significantly change the ocular surface. Cellular desquamation may not be affected by the presence of the rigid lens, which moves on the cornea, rubbing the epithelial layer rather than providing a bandage effect. Since few Japanese patients now wear PMMA lenses, which are known to lower the oxygen pressure, we did not study them.

Spindle-shaped cells have been observed with specular microscopy in such conditions as postpenetrating keratoplasty, post-epikeratophakia, keratoconus, and after excimer laser photorefractive surgery. ${ }^{152526}$ Their presence is believed to be related to the wound healing process. In this study, spindle-shaped cells were observed in the aphakic EWSCL group. This may mean that abnormal cell proliferation and differentiation occurred, which required cell 


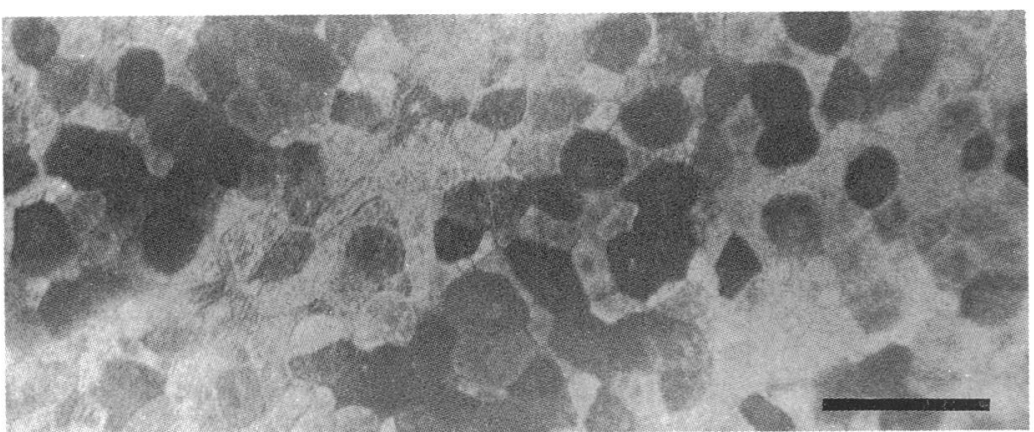

Fig $2 A$

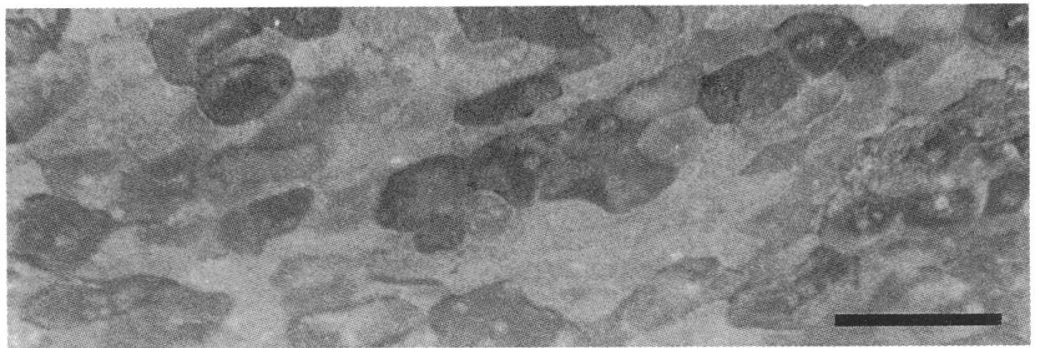

Fig $2 B$

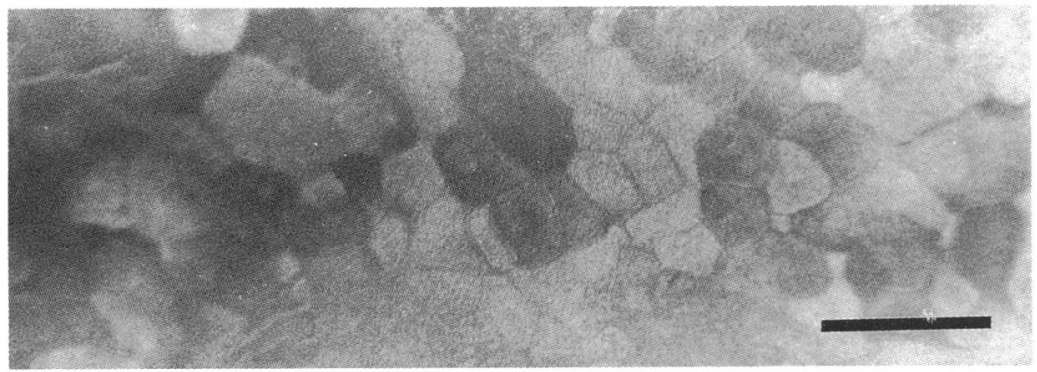

Fig 2C

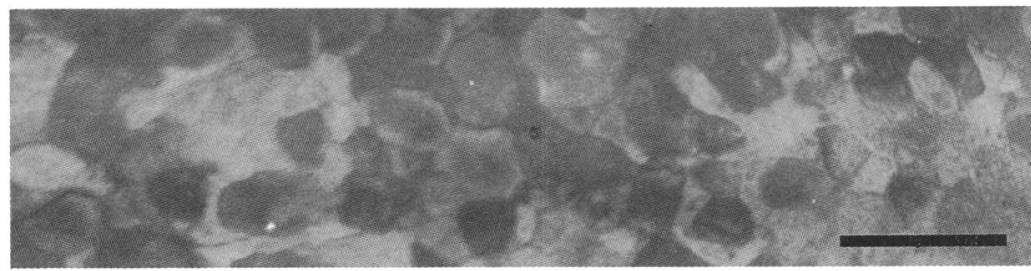

Fig 2D

Figure 2 Typical specular microscopic photographs of the corneal epithelium in aphakic controls and patients with extended wear contact lenses. Elongated and large cells are shown in Figures $2 B$ and $C$, whereas no apparent abnormalities were observed in Figure 2A. After the contact lens change, the epithelium recovered towards a normal configuration (Fig 2 D). Bar $=100 \mu \mathrm{m}$. (A) Control (female, 62 years old); (B) EWSCL (male, 61); (C) EWSCL (male, 60); (D) EWRCL for 3 months (same patient as in $B$ ).

Table 4 Morphometric analysis of corneal epithelium and endothelium: effects of changing lenses

\begin{tabular}{lll}
\hline & Epithelium $\left(\mu m^{2}\right)$ & Endothelium $\left(\mu m^{2}\right)$ \\
\hline Aphakic control & $654 \cdot 6(124 \cdot 4)^{\star}$ & $443 \cdot 8(48 \cdot 7)$ \\
EWSCL & $887 \cdot 9(156 \cdot 4) \dagger$ & $449 \cdot 8(51 \cdot 2)$ \\
EWRCL & $750 \cdot 1(125 \cdot 1) \dagger$ & $455 \cdot 2(53 \cdot 2)$ \\
\hline
\end{tabular}

${ }^{\star} \mathrm{p}<0.01 ;+\mathrm{p}<0.05$.

Table 5 Qualitative evaluation of corneal epithelium: effects of changing lenses

\begin{tabular}{lcc}
\hline Group & Elongated cells & Large cells \\
\hline Aphakic control & $0 \%(0 / 15)$ & $0 \%(0 / 15)$ \\
EWSCL & $53 \cdot 3 \%(8 / 15)$ & $100 \%(15 / 15)$ \\
EWRCL & $13 \cdot 3 \%(2 / 15)$ & $26 \cdot 6 \%(4 / 15)$ \\
\hline
\end{tabular}

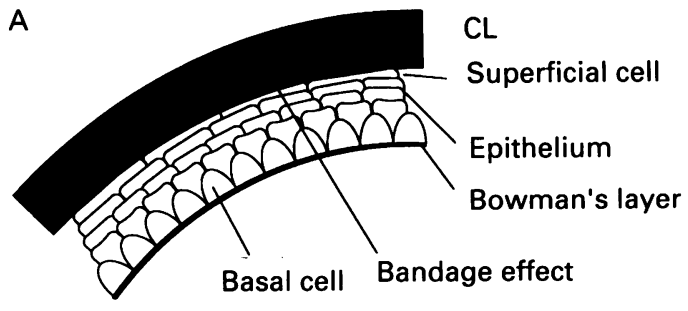

B

\section{Desquamation}

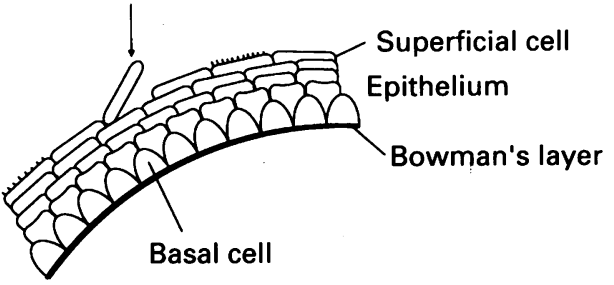

Figure 3 Schematic description of suppressed desquamation of corneal epithelium by EWSCL. The contact lens $(C L)$ covers the whole cornea, reducing the shearing force on the epithelial cells $(A)$. Without the contact lens, the cells are more susceptible to the shearing force of the lid movement $(B)$.

DWSCL, DWRCL, and EWRCL, as determined by specular microscopy. However, EWSCL cause enlargement of the superficial cells and this carries a significantly higher risk of ulcerative keratitis and any correlation should be studied in the future.

Presented in part at the Annual Meeting of the American Academy of Ophthalmology, Dallas, Texas, 10 November 1992.

This study was supported in part by grants from Uehara This study was supported in part by grants from Uehara
Memorial Foundation, the Ministry of Health, and the Ministry of Education, Culture and Science, Japan.

1 Dart J, Stapleton F, Minassian D. Contact lenses and other risk factors in microbial keratitis. Lancet $1991 ; 338: 650-3$.

2 Dunn J, Mondino B, Weissman B, Donzis P, Kikkawa D. Corneal ulcers associated with disposable hydrogel contact lenses. Am F Ophthalmol 1989; 108: 113-7.

3 Guillon M, Benjamin W. Contact lenses and keratitis. Lancet 1992; 338: 1146-7.

4 Poggio E, Glynn R, Schein O, Seddon J, Shannon M, Scardino $\mathrm{V}$, Kenyon $\mathrm{K}$. The incidence of ulcerative keratitis among users of daily-wear and extended-wear soft contact lenses. NEnglf Med 1989; 321: 779-83.

5 Schein O, Glynn R, Poggio E, Seddon J, Kenyon K. The relative risk of ulcerative keratitis among users of daily-wear and extended-wear soft contact lenses: a case-control study. a Englf Med 1989; 321: 773-8.

6 Holden BA, Mertz GW. Critical oxygen levels to avoid corneal edema for daily and extended wear contact lenses. Invest Ophthalmol Vis Sci 1984; 25: 1161-7.

migration from the peripheral cornea. The change of the lenses from EWSCL to EWRCL improved this condition. The clinical impression that the aphakic EWSCL group had the greatest risk of developing corneal ulcers is also consistent with this finding.

In conclusion, the corneal epithelium maintains its normal cellular configuration in nocturnal inflammatory constitutive tear fluid. Invest Ophthalmol Vis Sci 1992; 33: 626-40.

8 Butrus SI, Klotz SA. Contact lens surface deposits increase the adhesion of Pseudomonas aeruginosa. Curr Eye Res 1990; 9. 717-24.

9 Tsubota K, Yamada M, Naoi S. Specular microscopic observation of normal human corneal epithelium. Ophthalmology 1992; 99: 89-94.

10 MacRae SM, Matsuda M, Yee R. The effect of long-term hard contact lens wear on the corneal endothelium. CLAO f 1985; $11: 322-6$.

11 Matsuda M, MacRae SM, Inaba M, Manabe R. The effect of hard contact lens wear on the keratoconic corneal endothelium after penetrating keratoplasty. Am $\mathcal{f}$ Ophthalmol 1989; 107: 246-51.

12 Holden BA, Williams L, Zantos SG. The etiology of transient endothelial changes in the human cornea. Invest Ophthalmol Vis Sci 1985; 26: 1354-9.

13 Lemp MA, Mathers WD, Sachdev MS. The effects of contact lens wear on the morphology of corneal surface cells in the human. Trans Am Ophthalmol Soc 1990; 88: 313-22.

14 Tsubota K, Yamada M. Corneal epithelial alterations induced 1193-6.

15 Tsubota K, Yamada M, Naoi S. Specular microscopic observation of human corneal epithelial abnormalities.

16 Tsubota K. A contact lens for specular microscopic observation. Am 7 Ophthalmol 1988; 106: 627-8.

17 Alfonso E, Mandelbaum S, Fox MJ, Forster RK. Ulcerative keratitis associated with contact lens wear. Am F Ophthalmol 1986; 101: 429-33. by disposable contact lens wear. Ophthalmology 1992; 99 . Ophthalmology 1991; 98: 184-91. 
18 Glastonbury J, Crompton JL. Pseudomonas aeruginosa corneal infection associated with disposable contact lens use [Letter]. Aust NZ F Ophthalmol 1989; 17: 451.

19 Heideman DG, Verdier DD, Dunn SP, Stamler JF. Acanthameoba keratitis associated with disposable contact lenses. Am F Ophthalmol 1990; 110: 630-4.

20 Klotz S, Misra R, Butrus S. Contact lens wear enhances adherence of Pseudomonas aeruginosa and binding of lectins to the cornea. Cornea $1990 ; 9 \cdot 266-72$.

21 Hamano $H$, Hori $M$. Effect of contact lens wear on the mitoses of corneal epithelial cells: a preliminary report. CLAO $\mathcal{f}$ 1983; 9: 133-6.

22 Lemp M, Mathers W. Renewal of the corneal epithelium. CLAOF 1991; 17: 258-66.
23 Stern G, Lubniewski A, Allen C. The interaction between Pseudomonas aeruginosa and the corneal epithelium: an electron microscope study. Arch Ophthalmol 1985; 103: 1221-8.

24 Fleiszig S, Efron N, Pier G. Extended contact lens wear enhances pseudomonas aeruginosa adherence to human corneal epithelium. Invest Ophthalmol Vis Sci 1992; 33: 2908-16.

25 Tsubota $\mathrm{K}$. Corneal epithelium following intraepikeratophakia. $f$ Cataract Refract Surg 1991; 17: $460-5$.

26 Amano S, Shimizu K, Tsubota K. Corneal epithelium after excimer laser photorefractive keratectomy. $\mathrm{Am} f$ Ophthalmol 1993; 115: 441-3. 